\title{
OBJETIVO NAVAL: LA ISLA DE TRUK
}

\author{
Carolina Fontanals Riola \\ UnIVERSIDAD DE CÁDIZ
}

\section{RESUMEN}

La revisión histórica nos lleva a un escenario exótico en uno de los capítulos más estudiados de la Historia, la Segunda Guerra Mundial. Primero, la necesidad de aportar un relato más completo sobre dicho periodo histórico y, segundo, la trayectoria estadounidense en un escenario tan difícil como era el océano Pacífico nos brindan la oportunidad de mostrar al lector el determinante papel de la base nipona establecida en la isla de Truk.

La eliminación de este bastión inexpugnable se convertiría en una decisiva baza y en un determinante enfrentamiento entre titanes, otorgando la gloria y la fama al vencedor.

Palabras claves: Segunda Guerra Mundial, Guerra del Pacífico, Operación Hailstone, Truk, Islas Carolinas, Plan Z.

\section{ABSTRACT}

The historic revision carries us to an exotic setting in one of the most studied times of the History, World War Two. First, the need to contribute a more complete story on said historic period and about the American path in a setting as difficult as was the Pacific Ocean offer us the opportunity to show at the reader the determinant role of the Japanese base established in the island of Truk. The elimination of this unshakeable bastion would become a decisive trick in a determinant clash among titans, offering the glory and the fame to the victorious. Plan.

Keywords: World War II, Pacific war, Hailstone Operation, Truk, Carolina islands, Z

Toda seducción es azarosa y, aunque es indudable la aprensión del hombre por lo desconocido, el dominio de los mares ha sido uno de los sueños más perseguidos por los hombres a lo largo de la Historia.

Hubo una época en la que, incluso, el control del mar significaba también el control sobre la tierra; entonces, eran tiempos en que la talasocracia equivalía a la forma suprema del poder. 
Muchas han sido las anécdotas, relatos, poemas y mitos creados por el hombre a partir de la inspiración que produce la búsqueda desesperada, el afán de franquear el precipicio y extraviarse en el umbral de tierras y mares desconocidos, la tentación de riquezas insospechadas y, en definitiva, el poder acceder a un porvenir incierto sin impedir, más bien propiciando, la fuerza del azar.

Fueron, son y serán los seducidos aquellos a quienes debemos atribuir los descubrimientos de lugares tan recónditos como el Océano Pacífico y, en parte, ser los impulsores y grumetes de las Marinas que han protagonizado los capítulos más sonados de nuestra Historia.

La naturaleza marítima de la Segunda Guerra Mundial dio la oportunidad a muchas orillas, hasta la fecha solitarias, recónditas, desconocidas e incluso mitificadas, de darse a conocer al resto del mundo. En el caso concreto de la isla de Truk, tras el estallido de la guerra, pasaría a ser considerada como un auténtico frente dentro del teatro bélico del Pacífico.

Cuatro siglos antes (en $1668^{1}$ ), a bordo de varios navíos, el religioso español Diego Luís Sanvitores inicia el establecimiento de las misiones en las islas Carolinas sin sospechar en ningún momento el papel preponderante que adoptaría este pequeño bastión en el curso del segundo conflicto bélico por excelencia.

La información recogida a partir del descubrimiento de la isla de Truk, desde el siglo XVI hasta la fecha, nos revela como ésta gozaba de una interesante localización geográfica y estratégica por el simple hecho de estar formada por un cúmulo de pequeñas islas de gran altura, de una profunda laguna y de un filón de barrera que la circundaba, proporcionándole una increíble protección natural.

Tantas ventajas proporcionaba este enclave geográfico que muchas naciones, entre las que también incluimos el imperio español, se disputaron su soberanía en distintos periodos históricos. No sería hasta después de la Primera Guerra Mundial cuando dicho enclave despuntase como uno de los más deseados territorios para las superpotencias.

A las puertas de la Segunda Guerra Mundial, en Truk ondeaba la bandera nipona y, a pesar de la determinante prohibición de rearme impuesta por el Tratado de Versalles, en su irrisorio terreno se llevaría a cabo uno de los mas importantes procesos de militarización, en donde las características rapidez y ultra-secretismo llevarían a la isla a adoptar un notable papel y el título del Gibraltar del Pacífico.

\section{TRUK: EL ATOLÓN DEL MISTERIO}

El simple hecho de que en la campaña estadounidense llevada a cabo entre 1941-1945 en el océano Pacífico no se incluyera una invasión terrestre como se estaba llevando a cabo en anteriores y posteriores operaciones bélicas, junto al reducido número de pérdidas humanas como consecuencia de esta reconquista, ha llevado a los historiadores estadounidenses a trivializar la toma de la base japonesa de Truk, dejando constancia de un relato incompleto y sin destacar casi ninguno de los numerosos aspectos que existen sobre la épica batalla naval que resultó ser la defensa de este atolón.

Sister Maria Angélica Salaberría, M.M.B.: Time of Agony. Micronesian Area Research Center. University of Guam. 1994. 
Como hemos mencionado con anterioridad, la laguna de Truk estaba provista de unas características geográficas que la hacían terriblemente atractiva. Ésta constaba de cinco entradas de agua que proporcionaban una increíble protección natural y una más fácil defensa, lo que la hacían perfecta para una base naval; dicha protección se reforzaría con la construcción de fortificaciones en cada una de las entradas y de la aviación.

Y es que la isla de Truk se convirtió en un auténtico mito. El hecho de que no existiesen mapas del atolón (fue la Inteligencia Oficial americana ${ }^{2}$ quien proporcionó una estimación del enemigo) junto al hecho de que era vox populi que algo extraño se estaba gestando en la base nipona, difundiría un rumor amparado en la sospecha. Misteriosos desenlaces les esperaban a todos aquellos que osaban acercarse a sus costas, provocando que los supervivientes de estos desventurados y extraños sucesos resultasen ser los verdaderos difusores de este halo de misterio y quienes, a su vez, avivasen dicha leyenda a partir de numerosos, terroríficos e increíbles relatos sobre la isla.

La prensa mundial no tardaría en tratarla como una de las plazas fuertes más inquebrantables de la Segunda Guerra Mundial al certificar que dicho enclave estaba dotado de una defensa de magnánimas dimensiones basada en la numerosa aviación, cañones y exarcebados soldados que se suponían allí destacados. Con agrado comentamos el hecho de que podemos encontrar ejemplares de periódicos y documentos desclasificados de la época custodiados en la Hemeroteca Nacional en España y en Washington, respectivamente; en donde encontramos numerosos testimonios de cómo se transmitieron los acontecimientos.

Londres 17. 12 noche. La base japonesa de Truk posee, según se cree, instalaciones suficientes para acoger a todos los buques conocidos de la Flota nipona. Se conocen, sin embargo, pocos detalles de las instalaciones. Truk es pilar de la estrategia naval japonesa en el Pacífico Central. EFE. ${ }^{3}$

El brazo armado japonés, algo parecido a la poderosa línea Maginot europea pero en el Pacífico, era la auténtica clave del imperialismo nipón sobre el Pacífico y el mantenimiento del mismo descansaba en la labor de enclaves tan determinantes como era la isla de Truk. Esta base nipona, la más importante en el Pacífico, resultaría una de las hazañas más rentables ya que se convertiría en una base estratégica vital para el mantenimiento del imperio y para la continuación del mismo; mientras que, para los norteamericanos, era un obstáculo inimaginable en el camino de la flota aliada en su plan de reconquista.

La operación de limpieza iniciada por las fuerzas norteamericanas sobre el Pacífico Central desataría una importante ofensiva que desencadenaría más de un violento choque de fuerzas. Tal fue la dificultad y la importancia de la misma que su derrota ha obtenido la calificación de más de un estudioso como la de un auténtico Pearl Harbor japonés. ${ }^{4}$

RADM Reeve's. El nombre del oficial en jefe era LT Denius ("Denius the Genius").

ABC.Viernes 18 de Febrero.1944. Edición de la mañana. Página 10.

ABC. Viernes 18 de Febrero 1944. Edición de la mañana. Pág.10. 


\section{EEUU Y JAPÓN SE MIDEN LAS FUERZAS}

Japón era una creciente nación atosigada por las deficiencias económicas producto del acarreo que conllevaba, en primer lugar, coexistir con una numerosa y creciente población asentada en un exiguo porcentaje de tierras de producción de un país cuya superficie es muy limitada; y, en segundo lugar, el impedimento tanto comercial como industrial por parte de muchas otras naciones hacia Japón. Junto a estos factores no debemos tampoco olvidar otro determinante agente que muchos autores han venido calificando como orgullo racial, el cual siembra sus raíces en el ansiado sueño de Japón por ser dueño y señor de Extremo Oriente; un argumento suficiente para argüir el abandono del cerco geográfico que el pueblo blanco le había impuesto y la apertura de sus fronteras mediante el empleo de la fuerza.

El fulgurante resultado de dicha empresa no hizo más que empujar al titánico Japón hacia un incansable e irreducible avance a través del Próximo Oriente totalmente convencido de su grandeza y poderío; tal alarde era debido al amparo de la atractiva estela de victorias y lauros que iban sumando sus conquistas.

El nuevo imperio nipón parecía no tener dificultades ante potencia alguna. Al mismo tiempo, el plan norteamericano también parecía orientarse hacia un creciente afán imperialista y en el que, a su vez, se contemplaba esta área geográfica del Pacífico como objetivo final.

La versión norteamericana difundida de los hechos habla de la obligación estadounidense de defensa ante la amenazante expansión japonesa en la zona. Lo cierto es que el objetivo último del mando norteamericano se basaba en la reconquista de todas aquellas plazas que habían sucumbido al avance nipón en el océano Pacífico central, hacer pesar una amenaza continua sobre el enemigo para producir el efecto de dispersión, lograr la desaparición del Imperio del Sol Naciente y ampliar su campo de influencia sobre distintos puntos del Pacífico.

Truk es la base estratégica más importante del Japón. El ataque directo contra la isla debe considerarse como una tentativa osada de introducir una cuña en la base estratégica más importante que el Japón posee en los mares del Sur, pero al mismo tiempo la idea de la precipitación con que los norteamericanos intentan regresar a Manila.-EFE

Hasta finales del año 1943 no se daría comienzo a esta reconquista basada en un sistema de saltos con el que los estadounidenses se irían haciendo con más y más islas niponas en donde asentar sus bases aéreas. Este nuevo sistema definía el innovador método de guerra desarrollado por los Estados Mayores operativos en el Pacífico, el cual estaba basado en la inversión de todas las fuerzas estadounidenses (las cuales poseían un poder ofensivo bastante considerable) en la eliminación de Japón y Alemania y, por supuesto, la necesidad de repartir el mundo.

El avance estadounidense por el Pacífico central parecía ser, en un principio, una operación más fácil que ninguna otra ya que se trataba de pequeñas islas en la ruta y nada pa-

ABC. Domingo 20 de Febrero 1944. Edición de la mañana. Pág. 29. 
recía imponerse al aplastante avance naval aliado. En este venturoso viaje era imposible no hacer parada en la base de Truk.

Los servicios de inteligencia habían descubierto que muchas de las posiciones de estas islas eran atolones que por sus condiciones naturales resultaban indefendibles ante serios ataques pero idóneas como muelles de aeroplanos y submarinos. La flota estadounidense no tendría por qué tener grandes dificultades en capturarlas y sin emplear demasiadas tropas.

Dicho avance seguía un itinerario jalonado por las islas Gilbert, Marshall y Carolinas. En la práctica se demostró no ser una campaña tan fácil de lograr y que, además, era necesario un plan estratégico capaz de solventar y superar la complicada geografía que se quería conquistar. El almirante Nimitz, comandante en jefe de la flota estadounidense en el Pacífico central, secundado por una amplia perspectiva de éxitos en la zona, sería el encargado de poner en marcha dicho plan. La formidable fuerza invertida, aumentada por nuevas unidades y apoyada por una importante red logística, les daría a los aliados la superioridad aeronaval allí por donde avanzaban y la oportunidad de cumplir su deseo de acceder y rodear Truk por el sur y atacar las Palao. Se trataba de una operación jamás documentada a lo largo de toda la Historia.

\section{LA ESTRATEGIA NAVAL ALIADA SOBRE EL IMPARABLE IMPERIALISMO NIPÓN}

En el amanecer del año 1944, las fuerzas japonesas del área del Pacífico descansaban en las muy diversas bases establecidas en las islas de dicho océano y frente a ellas se erigía una de las flotas más potentes estadounidenses jamás vista en el Pacífico: la Task Force 58, la cual contaba con la tecnología, el material, los hombres... en definitiva, todo el potencial posible para hacer frente a uno de los imperios más poderosos de todos los tiempos.

Cabe destacar que en este enfrentamiento la Marina jugaría un papel decisivo en la contienda ya que, al tiempo que los estadounidenses apostaban en la guerra por el empleo masivo de portaaviones, los japoneses habían mejorado sus antiguas tácticas a partir de otras ajenas como la Blitzkreg de Hitler o los ataques fulminantes de la aviación británica; $y$, considerando que sus verdaderos portaaviones insumergibles eran sus innumerables islotes en el Pacífico, continuó en su línea y con idénticos efectivos.

Este hecho provocaría una seria desventaja que, con el acelerado ritmo que iba tomando el conflicto, daría la razón a la apuesta tecnológica norteamericana y precipitaría a Japón en la construcción de tantos portaaviones y acorazados como les fuese posible para hacer frente al vertiginoso poderío naval estadounidense.

Sin más tardar, el cuartel general nipón emitió un plan al que denominarían Plan Zen el que se fijaban las directrices para hacer frente al ataque aliado sobre el Pacífico Central y en donde, en resumen, la estrategia naval estaba basada en la concentración de todas las fuerzas aéreas y navales sobre el objetivo mientras que la acción en tierra tenía como factor sorpresa el uso del submarino, a pesar de la superioridad norteamericana.

El reparto de las fuerzas navales niponas de superficie dejaba a Truk con la XIV División de cruceros y destructores compartida con otros enclaves y la totalidad del grueso de 
la Flota Combinada compuesto por: los acorazados; las IV, V, VII y VIII Flotillas de Cruceros; la III División de Portaaviones; las II y IV Flotillas de Destructores; las I y III Flotillas de Submarinos. Con respecto a las fuerzas navales aéreas, en Truk encontramos el grueso de la XI Flota Aérea, o sea, las XXV y XXVI Flotillas.

En el momento en que todas las fuerzas de ambos rivales se desplegaban sobre el océano Pacífico, en un principio y a pesar de esa desigualdad tecnológica comentada, los japoneses contaban con una clara ventaja: la de poder maniobrar por líneas interiores y la de concentrar sus fuerzas aéreas en los puntos amenazados, hecho que finalmente no sabrían contrarrestar por su ignorancia con respecto a los puntos exactos en que atacarían los norteamericanos.

La operación norteamericana sobre las islas Carolinas fue puramente naval y su método consistió en colocar sus poderosos portaaviones cerca del objetivo y desde allí enviar sus oleadas de aviones. La Task Force comprendería la fuerza principal estadounidense. Esta estaba abanderada por el portaaviones estadounidense Iowa y formada por 9 portaaviones más 7 buques de guerra, junto a una apropiada fuerza de exploración, toda la tripulación y la aviación que dichas naves albergaban. En el caso concreto del ataque a la isla de Truk, sería el portaaviones USS Enterprise CV6 quien haría las veces de navío de escolta para la aviación aliada en el momento del ataque sobre el objetivo, asumiendo funciones de proveedor de aviones. La flota de aviones aliados estaba formada por aviones de ataque B-24, aviones de búsqueda PBY, Curiser SOC y aviones de rescate OS2U.

Queremos insistir en la reticencia histórica que existe ante la importancia de dicho capítulo bélico y rescatar las declaraciones pronunciadas por el mismísimo secretario de la Marina estadounidense, el coronel Knox, tras el ataque a la base nipona de Truk, para reforzar nuestra teoría acerca de la importante baza de dicha base en el desarrollo de la Guerra del Pacífico y de la Segunda Guerra Mundial. Además, mostrar al lector la otra cara de la historia.

Knox comentaba que realizaron la ofensiva en el momento y el lugar que escogieron añadiendo que lo de Truk fue una victoria. El ataque contra Truk, efectuado por aparatos de los navíos portaaviones, es significativo y prueba que nuestra potencia aeronaval se acrecienta y está en situación de proyectar su fuerza hacia el Oeste. Aquella operación es no más que uno de los ataques dentro de la campaña general, cuyo objetivo es destruir la posibilidad de que el enemigo pueda continuar sus operaciones en el mar, en la tierra o en el aire. $\mathrm{EFE}^{6}$

A partir de estas declaraciones se ensalzaría la importancia de la aviación militar y de los portaaviones en este capítulo bélico; la victoria sobre Truk era una prueba fehaciente de la creciente potencia aeronaval contra cualquier atisbo de imperialismo naval, terrestre o aéreo de Japón.

\section{LA OFENSIVA AMERICANA: TRUK, EL GIBRALTAR DEL PACÍFICO}

La Flota del Pacífico ha devuelto a Truk la visita hecha por la flota japonesa a Pearl Harbor... ${ }^{7}$ 
Inmediatamente se hubo producido el ataque a Pearl Harbor, los norteamericanos no concedieron ni un respiro a los japoneses ya que inmediatamente se pondría en marcha un plan de ataque en donde también se contemplaba acabar con aquellos puntos vitales con los que demoler ese hostigador imperio nipón.

El periódico español $\mathrm{ABC}$ relataba:

Ataque naval con Truk (Carolina). Washington 17 de Febrero, 11 de la noche. El departamento de Marina anuncia que fuerzas navales norteamericanas han atacado Truk, gran base naval japonesa en el corazón del archipiélago de las Carolinas. El ataque comenzó ayer. EFE

Washington 17 de Febrero, 11 de la noche. El texto del comunicado hecho público por el departamento de Marina dice:

En la mañana del día de ayer, potentes fuerzas navales de la Flota norteamericana del Pacífico comenzaron un ataque contra la base naval japonesa de Truk, con la intervención de varios centenares de nuestros aviones. No hay más detalles. ${ }^{8}$

Ciertamente, Truk era un difícil obstáculo y así lo había reconocido el servicio de inteligencia estadounidense en Washington. El hecho de que se atacase directamente y cada media hora este objetivo era una consecuencia directa ante la tentativa aliada por introducir una cuña en la base estratégica más importante que el Japón poseía en los mares del Sur y, al mismo tiempo, una vía de acceso a otro gran objetivo en la carretera hacia Tokio: Manila.

El consecuente parte japonés, también reflejado en la prensa española ${ }^{9}$, junto a los testimonios ofrecidos por veteranos de guerra como el caso del señor Jack Glass ${ }^{10}$, veterano estadounidense de la guerra del Pacífico, han sido recogidos como documentación de gran interés de forma que se pudiese lograr completar el relato de un conflicto digno de recordar.

El 4 de Febrero de 1944, dos aviones de clase PB4Y se embarcaron en un vuelo de reconocimiento sobre la base naval de Truk. Lograron comprobar la existencia de un amplio número de barcos de guerra en la laguna de Truk, incluyendo barcos de tonelada 71.659 como el Mushashi y 2.800 de tripulación, además de barcos mercantes y de transporte. También se pudo documentar un gran número de aviones nipones y varias pistas de aterrizaje.

En el amanecer del día 17 de Febrero de 1944 en el Pacífico central y a cien millas de la base nipona de Truk, una imparable Task Force daría comienzo a la denominada ope-

ABC. Viernes 18 de Febrero 1944. Edición de la mañana. Pág. 10.

Tokio 18 de Febrero, 1 tarde. El Cuartel General imperial comunica:

Fuerzas aéreas enemigas atacan la isla de Truk, en el archipiélago de las Carolinas, desde la mañana del día de ayer, 17 de Febrero. Se carece de detalles acerca del desarrollo de la batalla. EFE

ABC. Sábado 19 de Febrero 1944. Edición de la mañana. Pág. 12.

10 Según extraemos de la conversación mantenida con el veterano estadounidense de Guerra Jack Glass. Con apenas 19 años fue destinado como radio-operador de primera clase en aviación a bordo del bombardero SBD en el portaaviones USS ENTERPRISSE. Participó en seis bombardeos a la base de Truk. 
ración Hailstone. Los navíos que conformaban la Task Force 58 emplearían la denominada táctica por turnos, que daría salida a un importante número de aviones F6F Hellcats que invadirían, en cuestión de una hora, el espacio aéreo de este enclave.

Con la lección bien aprendida tras el fulminante ataque nipón sobre Pearl Harbor, una bien dotada aviación norteamericana aprovecha el factor sorpresa frente a la importante base estratégica de Truk y ataca rápidamente con sus poderosas formaciones de aviones embarcados en portaaviones. El enemigo se encontró repitiendo constantemente sus raids con varios centenares de cazas y bombarderos...La situación de la guerra había alcanzado una gravedad sin precedentes... El ritmo de las operaciones enemigas se encontraba ya asediando la zona vital japonesa.

Desde 5.000 metros de altura los bombarderos de clase Dauntless y los torpederos de clase Avenger soltaban su munición sobre los barcos japoneses que operaban en ese momento en Truk, incendiando con sus bombas cualquier infraestructura que pudiese albergar cualquier atisbo de reconstrucción de la fuerza nipona sobre la isla.

La increíble respuesta de los antiaéreos japoneses, desplegados tanto en tierra como en los barcos, junto a la extendida fama acerca de la pasión y la entrega de los soldados nipones, no dejarían ni un solo segundo de atormentar la angustia de los pilotos estadounidenses ante el temor de ser abatidos y cogidos presos.

La confusión y la sorpresa se apoderan de los medios y de su público. La prensa japonesa se hacía eco de este nuevo ataque aliado argumentando su importancia debido al fuerte interés nipón por hacer ver y comprender a sus lectores que la táctica aliada de pasar en el centro del Pacífico de una isla a otra se diferenciaba de la empleada anteriormente en la zona de las Salomón.

Ahora no se ha luchado por cada una de las bases isleñas, sino que el enemigo, pasando por alto las pequeñas islas, se ha dirigido contra objetivos mayores. - EFE ${ }^{11}$

Mientras tanto, en los diarios estadounidenses se hacía alarde del poderío de sus tropas. Así rezaban los titulares españoles:

Washington 17, 12 noche. En los medios navales norteamericanos de Washington se cree que el ataque contra Truk es uno de los golpes más audaces que se han dado en la guerra del Pacífico. ${ }^{12}$

A pesar de las opiniones generalizadas estadounidenses, muchos somos conscientes de que en ningún momento dicho valor ha resultado exagerado, ya que los propios japoneses llegaron a considerar este enfrentamiento como una de las más difíciles y duras experiencias de la guerra en el Pacífico. La cuestión radica en que la base instalada en las islas Carolinas, Truk, simbolizaba el pilar de la estrategia naval nipona que tantos éxitos les había proporcionado en el Pacífico Central.

Tras la primera oleada de ataques se continuó, en la nocturnidad, con un incesante fuego sobre las humeantes construcciones, barcos, aviones en ruinas. Las defensas japone-

11 ABC. Domingo 20 de Febrero 1944. Edición de la mañana. Pág. 29.

12 ABC. Viernes 18 de Febrero 1944. Edición de la mañana. Pág. 10. 
sas estaban inservibles y tras el ataque del día anterior pocos eran los navíos dotados de antiaéreos que les pudiesen hacer frente.

Los japoneses no descubrieron a las fuerzas norteamericanas cuando éstas comenzaban a aproximarse. En el curso de los ataques del 16 y 17 de Febrero, nuestros aparatos procedentes de portaaviones destruyeron por lo menos 201 aviones enemigos, 127 de los cuales fueron derribados en combates aéreos. Además, fueron averiados en el suelo más de 50 aparatos. El enemigo no ofreció resistencia aérea al segundo día del ataque.

Los barcos de superficie hundidos al adversario son los cruceros ligeros, tres destructores, un transporte de munición, un barco de aprovisionamiento de hidroaviones, de petroleros, dos cañoneros y ocho mercantes. Han sido, además, probablemente hundidos, los siguientes buques: un crucero o gran destructor, dos petroleros y cuatro mercantes. Por nuestra parte, hemos perdido diecisiete aviones. Ninguno de nuestros barcos ha sido hundido, aunque uno de ellos sufrió daños ligeros. $-E F E .^{13}$

La balanza se inclinaba irreversiblemente a favor de las fuerzas aliadas y los japoneses, confundidos, no cesaron en retomar las riendas del Imperio relegando las fuerzas hacia otros puntos próximos, los cuales los rearmaban y los hacían base de las operaciones emprendidas con el fin de frenar el inquebrantable avance estadounidense.

¿Si las fuerzas estaban más o menos equilibradas y la mayoría de las bases niponas presentaban una temida defensa cómo es que, a pesar de los extasiantes esfuerzos de Japón, la guerra estaba ya casi perdida?

Ciertamente, el factor sorpresa resultaría de gran utilidad, pero el importante descubrimiento del radar ${ }^{14}$ llegó en un momento muy oportuno para los estadounidenses. Es sabido que los pilotos del Enterprise ${ }^{15}$ habían sido entrenados en el uso del radar en sus planes sobre el objetivo; ventaja, en cambio, que no sería empleada por los japoneses ya que si el descubrimiento europeo hubiese llegado a manos niponas y éste hubiese sido operacional, mantener un secreto como el ataque a Truk o a su homólogo Pearl Harbor hubiese sido realmente difícil, así como poder hacer efectiva la victoria en lugar de la derrota.

Finalmente, el ritmo de las operaciones se fue acelerando y los ataques a las islas Carolinas, aunque estuviesen neutralizadas, se sucederían hasta septiembre de 1944, cuando la fuerza norteamericana de portaaviones rápidos se paseaba por el Pacífico dirigiéndose hacia el siguiente objetivo: las islas Filipinas.

Con respecto al recuerdo histórico que ha llegado hasta nosotros, no dudamos de que en la empresa reconquistadora estadounidense enclaves como Guadalcanal o Iwo Jima resultaran de vital relevancia para llegar al corazón del imperio japonés, pero no aprobamos el hecho de que hayan sido los propios historiadores quienes se han encargado de dejar en el recuerdo estos nombres mientras han mantenido en el olvido otros cuyo papel resul-

13 Declaraciones del Almirante Nimitz recogidas por ABC. Martes 22 de Febrero 1944. Edición de la mañana. Pág. 20 .

14 Nunca antes en la historia una invención había tenido un papel tan significativo en el resultado de una batalla, al grado de que cambió el curso de la Segunda Guerra Mundial.

15 Así lo atestigua la numerosa bibliografía y el testimonio oral recogido a partir de la conversación mantenida con el veterano de guerra Jack Glass y su participación en el ataque a la isla de Truk durante la Segunda Guerra Mundial. 
tó igual o más decisivo en el desarrollo del plan. El simple hecho de que otras bases en manos niponas cayesen ante los ataques estadounidenses en intervalos de tiempo menores, o que las operaciones se llevasen a cabo con una mayor efectividad y con inmejorables resultados, no son motivos aparentes para que el resto de la humanidad no conozca y valore la tediosa lucha que se llevó a cabo, por ejemplo, en Truk. Toda la tecnología y los efectivos estadounidenses mencionados facilitaron en sumo grado, tanto en uno u otro escenario del Pacífico por muy remoto que estuviera uno del otro, el que lograsen salir victoriosos de la operación de limpieza iniciada por sus fuerzas y que se proclamasen principales artífices del desarme de uno de los mitos estratégico-navales más destacados durante la Segunda Guerra Mundial.

En conclusión, invitamos al lector a no olvidar que, ciertamente, los norteamericanos sobresalieron por el buen ritmo que habían alcanzado en operaciones anteriores y que no resultó tan irreducible la isla de Truk, pero el cara a cara de ambas potencias en este punto geográfico indudablemente resultó un choque violento y una gran derrota por la confianza que los japoneses pusieron en ella. 